\title{
The effect of the macrobiotic Ma-Pi 2 diet vs. the recommended diet in the management of type 2 diabetes: the randomized controlled MADIAB trial
}

\author{
Andreea Soare ${ }^{1}$, Yeganeh M Khazrai ${ }^{1}$, Rossella Del Toro', Elena Roncella', Lucia Fontana², Sara Fallucca', \\ Silvia Angeletti ${ }^{3}$, Valeria Formisano ${ }^{1}$, Francesca Capata ${ }^{1}$, Vladimir Ruiz ${ }^{4}$, Carmen Porrata ${ }^{5}$, Edlira Skrami ${ }^{6}$, \\ Rosaria Gesuita ${ }^{6}$, Silvia Manfrini ${ }^{1}$, Francesco Fallucca ${ }^{7}$, Mario Pianesi ${ }^{8}$ and Paolo Pozzilli ${ }^{1 *}$ for the MADIAB Group ${ }^{1}$
}

\begin{abstract}
Background: Diet is an important component of type 2 diabetes therapy. Low adherence to current therapeutic diets points out to the need for alternative dietary approaches. This study evaluated the effect of a different dietary approach, the macrobiotic Ma-Pi 2 diet, and compared it with standard diets recommended for patients with type 2 diabetes.

Methods: A randomized, controlled, open-label, 21-day trial was undertaken in patients with type 2 diabetes comparing the Ma-Pi 2 diet with standard (control) diet recommended by professional societies for treatment of type 2 diabetes. Changes in fasting blood glucose (FBG) and post-prandial blood glucose (PPBG) were primary outcomes. $\mathrm{HbA}_{1,}$ insulin resistance (IR), lipid panel and anthropometrics were secondary outcomes.

Results: After correcting for age, gender, BMI at baseline, and physical activity, there was a significantly greater reduction in the primary outcomes FBG $(95 \% \mathrm{Cl}: 1.79 ; 13.46)$ and PPBG $(95 \% \mathrm{Cl}: 5.39 ; 31.44)$ in those patients receiving the Ma-Pi 2 diet compared with those receiving the control diet. Statistically significantly greater reductions in the secondary outcomes, $\mathrm{HbA}_{1 \mathrm{c}}(95 \% \mathrm{Cl}: 1.28 ; 5.46)$, insulin resistance, total cholesterol, LDL cholesterol and LDL/HDL ratio, BMI, body weight, waist and hip circumference were also found in the Ma-Pi 2 diet group compared with the control diet group. The latter group had a significantly greater reduction of triglycerides compared with the Ma-Pi 2 diet group.
\end{abstract}

Conclusions: Intervention with a short-term Ma-Pi 2 diet resulted in significantly greater improvements in metabolic control in patients with type 2 diabetes compared with intervention with standard diets recommended for these patients.

Trial registration: Current Controlled Trials ISRCTN10467793.

Keywords: Fasting blood glucose, Macrobiotic diet, Type 2 diabetes

\section{Background}

Type 2 diabetes is currently one of the most challenging problems facing national healthcare systems worldwide [1]. Nutritional therapy (as part of life-style intervention), with or without additional drug treatment, represents an effective option for managing this disease [2]. Formulating a universal diet for type 2 diabetes patients

\footnotetext{
*Correspondence: p.pozzilli@unicampus.it

1 Department of Endocrinology and Diabetes, University Campus Bio-Medico, Via Alvaro del Portillo 21, 00128 Rome, Italy

Full list of author information is available at the end of the article
}

can be difficult, since cultural preferences and economic conditions influence patient acceptance of, and adherence to, recommended diets [3].

In general, consumption of healthy, plant-based diets which are low in saturated fat and refined carbohydrates but high in whole grains, vegetables, legumes and fruits, coupled with appropriate exercise regimens, is recommended for patients with type 2 diabetes [4-7]. Additionally, reduction in the intake of carbohydrates with a high glycemic index has been shown to result in significant improvements in glucose tolerance and body weight 
when compared with conventional low-fat diets with similar energy content [8]. The International Diabetes Federation (IDF) and the American Diabetes Association (ADA) have issued diet recommendations for patients with type 2 diabetes $[9,10]$, however, alternative approaches need to be investigated because of the frequent low adherence of the currently recommended diets in the management of type 2 diabetes [11].

Macrobiotic diets, originally derived from an ancient Eastern philosophy of life, and updated for Western culture by the Japanese philosopher Georges Ohsawa [12], contain a large proportion of whole grains. The Ma-Pi 2 diet, conceived by Mario Pianesi, is a kind of macrobiotic diet; it is high in dietary fiber, which is in line with dietary recommendations by the Academy of Nutrition and Dietetics [13]. High-fiber diet may induced several health benefits such as prevention or reduction of bowel disorders and decreased risk of the development of coronary heart disease and type 2 diabetes $[14,15]$. The Ma-Pi 2 diet is also rich in complex carbohydrates, whole grains, vegetables and legumes, fermented products, sea salt and green tea, without fat or protein from animal sources (including milk and dairy products) and no added sugars. These features are designed to achieve optimal glucose control, lower insulin requirement, prolong the time of glucose absorption, increase insulin sensitivity, reduce total cholesterol and triglyceride levels in plasma, improve body weight control and lower systemic blood pressure [16-19]. Additionally, the Ma-Pi 2 diet appears to have antioxidant properties and prebiotic or probiotic effects [20]. This may alter the composition of gut microbiota, which in turn may affect the glycemic control $[21,22]$.

In previous uncontrolled intervention studies of 3weeks' duration, patients with type 2 diabetes following the Ma-Pi 2 diet have exhibited reduced $\mathrm{HbA}_{1 \mathrm{c}}$, cholesterol, triglycerides, and blood pressure $[23,24]$. We report here on the first randomized comparative trial which compares the Ma-Pi 2 diet with the dietary guidelines for type 2 diabetes recommended by professional societies in Italy [25].

\section{Methods}

\section{Trial design}

The study was a 21-day, controlled open-label trial in which participants were randomized (1:1 ratio) to the Ma-Pi 2 macrobiotic diet or to a diet based on dietary recommendations guidelines for type 2 diabetes [25]. The trial took place in the spring of 2013 at 2 closed site hotels in Italy. Throughout the trial, participants stayed at two different hotels according to the type of diet they were randomized to. The hotels were localized in the same geographic area, very close to each other, approximately a 20 minutes' drive distance between them. Patients were recruited from the Endocrinology and
Diabetes Department at University Campus Bio-Medico. The trial was conducted in accordance with the Declaration of Helsinki and the Good Clinical Practice guidelines and approved by the Institutional Review Board of University Campus Bio-Medico.

\section{Inclusion and exclusion criteria}

Overweight or obese (BMI 27-45 kg/m²) males and females, aged 40-75 years affected by type 2 diabetes were recruited by the medical team during regular visits to the Department of Endocrinology and Diabetes of the University Campus Bio-Medico in Rome, Italy. Additional inclusion criteria were a diagnosis of type 2 diabetes at least 1 year prior to the start of the trial and management with dietary intervention, oral hypoglycemic drugs (OADs), or both for 6 months prior to study entry. Identification of the presence of associated metabolic syndrome was made in accordance to the National Cholesterol Education Program Adult Treatment Panel III criteria, even though it was not an inclusion criteria [26]. Exclusion criteria included current use of insulin, or use at any time in the 2 years prior to the study, current use of corticosteroid therapy or any other drug that could interfere with carbohydrate metabolism, alcohol abuse, pregnancy, or already following a macrobiotic diet.

\section{Interventions}

Participants' eating habits prior to study entry were assessed using qualitative and quantitative questionnaires, and the energy and nutritional content of their diet was evaluated based on the answers given. Group assignment to treatment was blinded for personnel involved in collection of follow-up data and for personnel analyzing blood samples until data was locked for statistical analysis.

Participants were randomized to either the Ma-Pi 2 diet or a control diet according to the dietary guidelines for type 2 diabetes. The Ma-Pi 2 diet consisted of whole grains, vegetables and legumes. Beicha tea (roasted green tea) represented the main source of liquids, while the control diet was adapted to the Mediterranean culinary style. For both groups, energy intake was restricted by limiting calories to $1900 \mathrm{kcal} /$ day and $1700 \mathrm{kcal} /$ day for males and females, respectively. The diets were isocaloric but differed in nutrient composition. Ma-Pi 2 diet derived $72 \%$ of energy from carbohydrate, $18 \%$ from fat, and $10 \%$ energy from protein, fiber equal to $30 \mathrm{~g} / 1000 \mathrm{kcal}$, while the control diet $50 \%$ from carbohydrate, $20 \%$ from protein, and $30 \%$ from fat, fiber $\geq 20 \mathrm{~g} / 1000 \mathrm{kcal}$. Alcohol consumption was forbidden. Both diets provided 5 meals per day, with energy intake being divided between meals, $20 \%$ calories at breakfast, 30\% calories at lunch and 30\% calories at dinner. Two snacks were administered at approximately 2.5 hours after breakfast and lunch, respectively, each contributing $10 \%$ of the calories per day (Additional file 1). 
A 10-days menu cycle was devised for both diets and then repeated at the end of the period for another 11 days. Each daily menu was carefully planned and completed with recipes for each dish. Nutritional analysis and menu planning was developed with MètaDieta ${ }^{\circledR}$ Software using the Italian Food Composition Tables edited by the National Institute for Food and Nutrition Research (INRAN) [27]. Each menu cycle was ready a week before the beginning of the study to ensure that each recipe was tested by the cooks in order to reproduce it consistently. At this stage and throughout the intervention study, dietitians checked and weighed each portion size before and after cooking to make sure that subjects in both groups consumed equivalent amounts of energy and that macronutrient content was respected. Each subject was informed that a plate waste greater than or equal to $5 \%$ of the total daily food amount meant dismissal from the trial. Throughout the trial, participants stayed at two different hotels according to the type of the diet they were randomized. Meal consumption was strictly controlled in order to evaluate dietary compliance during the trial. Participants had their meals together with physicians and dietitians who could check their adherence to study protocol. Dietary adherence was defined as absence of any transgression from the assigned diet. Those subjects who attended meal session for fewer than 20 out of 21 days were considered nonadherent.

Participants were asked not to alter their exercise habits during the intervention period. Physical activity was assessed daily using a pedometer (Tri-axial activity monitor XL-18/XL-18 CN-AND A\&D Medical-California-USA). In addition they were instructed to continue their prestudy OAD doses without modification throughout the study, unless hypoglycemic symptoms were accompanied by a capillary glucose reading $<70 \mathrm{mg} / \mathrm{dL}$. In such cases hypoglycemic medications were reduced for participant safety.

\section{Outcome measures}

The primary outcomes of this study were the percentage change in Fasting Blood Glucose (FBG) and Post Prandial Blood Glucose (PPBG) levels from baseline (T0) to the $21^{\text {st }}$ day of treatment (T21) in Ma-Pi 2 group compared to the control group. Secondary outcomes included percentage change from baseline in plasma concentrations of $\mathrm{HbA}_{1 \mathrm{c}}$, total cholesterol, LDL cholesterol (LDLc), HDL cholesterol (HDLc), LDL/HDL ratio, and percentage change from baseline of insulin resistance, body weight, BMI, waist and hip circumference, and number of patients who achieved target values of FBG $\leq 110 \mathrm{mg} / \mathrm{dl}$ and $\mathrm{PPBG} \leq 140 \mathrm{mg} / \mathrm{dl}$.

FBG and PPBG were measured daily from T0 to T21 by the medical staff using capillary blood glucose meters (Bluecare, Biochemical Systems International, Arezzo, Italy). The fasting blood glucose was measured right before meals and the post-prandial blood glucose was measured 2-h after lunch. For all participants, venous blood samples were obtained early in the morning after a 12 hour fasting period. All biochemical and anthropometrical measures were assessed at T0 and T21 by the central laboratory (University Campus Bio-Medico, Rome). Insulin resistance was calculated using the homeostasis model assessment of insulin resistance (HOMA-IR) [28].

Body weight was measured at T0 and T21 before breakfast using a digital scale accurate to $0.1 \mathrm{~kg}$, waist circumference was measured with a tape measure placed $2.5 \mathrm{~cm}$ above the umbilicus. Hip circumference was measured at the maximal protrusion of the buttocks.

All patient and investigator-reported adverse events (AEs) were recorded at each visit.

\section{Statistical analyses}

This study required 28 randomized patients per group with $80 \%$ power to detect a difference of at least 12 percentage points reduction in mean FBG and PPBG from baseline between Ma-Pi 2 and control groups (with a 2sided type I error at 0.05), assuming a standard deviation of $\leq 15 \%$ and a maximum dropout rate of $11 \%$.

To detect a 0.25 percentage point between-group difference in $\mathrm{HbA}_{1 \mathrm{c}}$ from baseline (the main secondary endpoint) with $80 \%$ power, a $\mathrm{p}$ value at the $5 \%$ level with an assumed SD of $0.3 \%$ and $10 \%$ estimated withdrawal, 27 participants were required per group.

The primary analysis was based on a modified intention-to-treat principle and it was carried out for all patients who had FBG and PPBG results for at least the first week following randomization. A non-parametric approach was chosen for the statistical analysis since outcome variables were found to be of non-normal distribution (using the Shapiro test). Quantitative variables were summarized using percentiles (median and interquartile range). Comparisons between treatment groups were performed using the Wilcoxon rank-sum test and 95\% confidence intervals ( $95 \% \mathrm{CI}$ ) for median values. Absolute and percentage frequencies were used for qualitative variables and the Fisher exact test was applied for group comparisons.

The 2 groups were compared at T0 to test whether patients were similar in terms of demographic and anthropometrics characteristics, and lipid and carbohydrate metabolic parameters. The percent variations between values measured at T0 and T21 were calculated as efficacy variables for the primary (FBG and PPBG), and secondary end-points $\left(\mathrm{HbA}_{1 \mathrm{c}}, \mathrm{HOMA}-\mathrm{IR}\right.$, total cholesterol, LDLc, HDLc, LDL/HDL ratio, triglycerides, BMI, waist and hip circumference).

A bivariate analysis was performed to compare measures changes between the Ma-Pi 2 diet group and the control group and results were graphically represented 


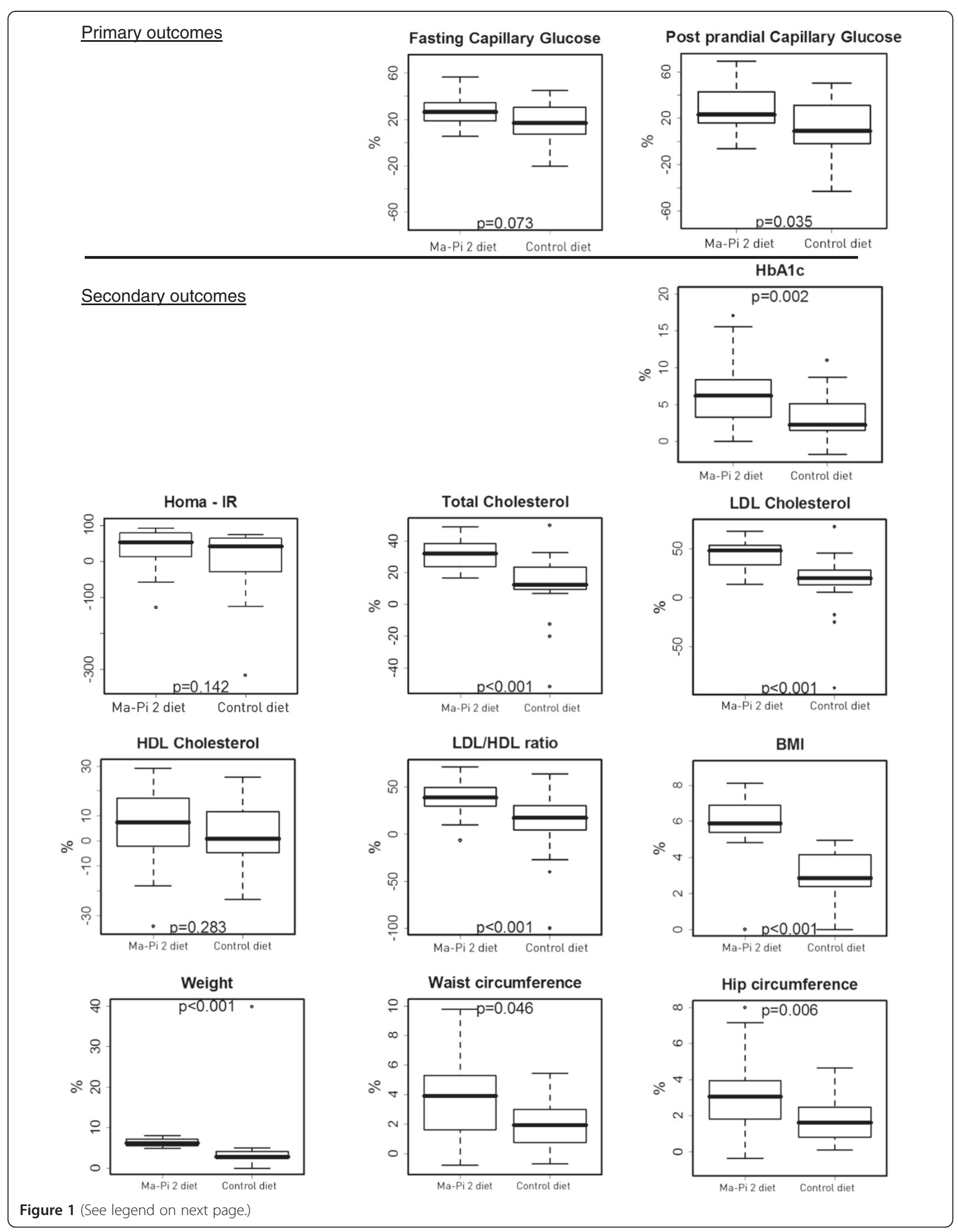


(See figure on previous page.)

Figure 1 Reduction in primary and secondary outcomes from baseline to T21 in the Ma-Pi 2 group vs. controls. Primary outcomes -

Percentage change in FBG and PPBG from baseline to T21 in the Ma-Pi 2 group vs. control group. The figure represents the results of the bivariate analysis when the Ma-Pi 2 and control groups were compared in the percentage change between T0 and T21 of the efficacy variables (non-adjusted values). Secondary outcomes - Percentage change in $\mathrm{HbA}_{1}$, lipid panel, BMl, weight, hip circumference and waist circumference from baseline to T21 in the Ma-Pi 2 group vs. control group. The figure represents the results of the bivariate analysis when the Ma-Pi 2 and control groups were compared in the percentage change between T0 and T21 of the efficacy variables (non-adjusted values).

by means of box-plots (Figure 1). A linear quantile regression analysis [29] was performed to estimate the effect of the diet (Ma-Pi 2 vs. control, explanatory variable) on the median percentage change occurred in each measured variable as (dependent variables), between T0 and T21. Each model was adjusted for those variables that could potentially affected the percent changes in the dependent variables, i.e. gender, age, BMI at baseline, and physical activity done by subjects during 21 days of the treatment (measured as the median number of kilometers walked per day). When HOMA-IR was analyzed, the wrist circumference was included in the model as covariate for adjustment. Wrist circumference is recognized a valid and easy marker to measure insulin resistance [30,31]. The results of linear quantile regression analysis were expressed as point and interval estimates of regression coefficients; when the coefficient was positive, the measured variable reduction was related to Ma-Pi 2 diet effect and when the coefficient was negative the reduction was related to the control diet. When the 95\% CI's did not include zero, regression coefficients were considered statistically significant (Table 1).

Patients with values of FBG $\leq 110 \mathrm{mg} / \mathrm{dl}$ and of PPBG $\leq 140 \mathrm{mg} / \mathrm{dl}$ were considered to have reached target values. Group comparisons in terms of percentage of patients achieving and maintaining those target levels after 21 days were performed using McNemar's test to estimate the differences between proportions in the 2 groups and their relative 95\% CI's; when the 95\% CI's did not include zero, the differences were statistically significant (Table 2).

A ranked-based nonparametric analysis for longitudinal data was used to compare the time trend in absolute values of FBG and PPBG over 21 days of dietary intervention in Ma-Pi 2 and control groups. The effect of diet, time and their interaction were evaluated; results were graphically represented by plotting the median values of the daily measurements of FBG and PPBG in the two groups (Figure 2).

All statistical analyses were performed using $\mathrm{R}$ statistical package (Foundation for Statistical Computing, Vienna, Austria) and statistical significance was assessed at a level of probability of 0.05 .

\section{Results}

A total of 200 patients were screened and 56 were considered eligible for recruitment.
Baseline demographic and clinical features of patients are presented in Table 3 . There were no significant differences between groups. Analysis of diets in the 6 months prior to the trial showed little difference between groups, with an average daily energy intake of 1988 (SD 368.2) kcal for the Ma-Pi 2 group and 1964 (SD 294.3) kcal for the control group ( $\mathrm{p}=0.802$ ). Nutritional composition was also similar in the Ma-Pi 2 group (18.2\% protein, $36.2 \%$ fat, $45.6 \%$ carbohydrate, $10.3 \mathrm{~g} / 1000 \mathrm{kcal}$ of fiber) versus the control group (19.3\% protein, $35.4 \%$ fat, $45.3 \%$ carbohydrate, $10.8 \mathrm{~g} / 1000 \mathrm{kcal}$ of fiber).

The 56 eligible patients were randomly assigned to the Ma-Pi 2 diet group $(n=28)$ and the control group $(n=28)$. Reasons for exclusion were failure to meet inclusion criteria ( $n=90)$, inability to attend residential schedule $(n=45)$, and failure to keep interview appointment $(n=9)$. The CONSORT diagram reflecting flow of study participants through the study is shown in Figure 3. Both groups experienced drop outs after randomization but before receiving any intervention; 3 patients in the Ma-Pi 2 diet group and 2 in the control group. Reasons for discontinuation included patient reluctance to change diet (1 patient in the Ma-Pi 2 group) and personal problems that prevented patients remaining in the assigned hotel for the study duration (2 patients in the Ma-Pi 2 group and 2 patients in the control group). Therefore a total of 51 patients, 25 in the Ma-Pi 2 group and 26 in the control group, completed the trial and were included in the modified ITT (mITT) analysis. The modified intention-to-treat was carried out for all patients who had FBG and PPBG results for at least the first week following randomization.

Daily average energy intake during the trial was 1803 (SD 95.2$) \mathrm{kcal}$ (11.8\% protein, $15.2 \%$ fat, and $73.0 \%$ carbohydrates, with $29 \mathrm{~g} / 1000 \mathrm{kcal}$ fiber) in the Ma-Pi 2 group, and 1798 (SD 106.3) kcal (18.4\% protein, 32.3\% fat, and $49.3 \%$ carbohydrates, with $20.5 \mathrm{~g} / 1000 \mathrm{kcal}$ fiber) for the control group ( $\mathrm{p}=0.860$ ). For the Ma-Pi 2 diet the daily average amount of carbohydrate was $335.7 \mathrm{~g}$. As for the control diet the daily average amount of carbohydrate was $235.8 \mathrm{~g}(\mathrm{p}<0.001)$.

Figure 1 shows the primary and secondary outcomes results. A significant reduction was observed in both groups for FBG and for PPBG. The reduction in PPBG $(\mathrm{p}=0.035)$ levels was significantly greater in patients in the Ma-Pi 2 group compared with those in the control group. 
Table 1 Effect of Ma-Pi 2 vs. control diet on primary and secondary outcomes

\begin{tabular}{lcc}
\hline Dependent variables (\% changes) & $\begin{array}{c}\text { Regression } \\
\text { coefficients }\end{array}$ & $\mathbf{9 5 \% \mathbf { C l } ^ { * * }}$ \\
\hline Fasting Blood Glucose $(\mathrm{mg} / \mathrm{dl})$ & 6.82 & $1.79 ; 13.46$ \\
Postprandial Blood Glucose $(\mathrm{mg} / \mathrm{dl})$ & 11.48 & $5.39 ; 31.44$ \\
$\mathrm{HbA}_{1 \mathrm{c}}(\%)$ & 3.46 & $1.28 ; 5.46$ \\
$\mathrm{HbA}_{1 \mathrm{c}}(\mathrm{mmol} / \mathrm{mol})$ & 3,08 & $1,21,5,13$ \\
HOMA-IR* & 15.14 & $3.65 ; 37.51$ \\
Total Cholesterol (mg/dl) & 18.61 & $11.52 ; 22.63$ \\
LDL Cholesterol (mg/dl) & 26.40 & $21.37 ; 34.50$ \\
HDL Cholesterol (mg/dl) & 4.82 & $-5.69 ; 10.22$ \\
LDL/HDL Ratio & 31.54 & $20.63 ; 36.52$ \\
Triglycerides (mg/dl) & -11.04 & $-24.41 ;-2.92$ \\
BMI (kg/m2) & 2.99 & $2.42 ; 3.59$ \\
Weight (kg) & 3.04 & $2.39 ; 3.58$ \\
Waist circumference $(\mathrm{cm})$ & 2.01 & $0.08 ; 3.17$ \\
Hip circumference (cm) & 1.22 & $0.4 ; 1.94$ \\
\hline
\end{tabular}

*Wrist circumference was included as covariate for HOMA-IR.

${ }^{*}$ Coefficients are statistically significant when the $95 \%$ Cl's does not include zero.

Legend: Results of multiple quantile regression analysis evaluating the effect of Ma-Pi 2 diet on the percentage changes (T0-T21) in biochemical and anthropometrical measures using a multiple quantile regression model (adjusted value for age, gender, physical activity and BMI at baseline).

Regarding secondary outcomes, the Ma-Pi 2 group showed a significantly greater reduction in $\mathrm{HbA}_{1 \mathrm{c}}(\mathrm{p}=0.002)$ levels compared with those in the control group. Significantly greater median percentage reductions were observed for total cholesterol, LDLc, and the LDL/HDL ratio in the Ma-Pi 2 group versus the control group ( $\mathrm{p}<0.001$ ). No significant change was observed for HDLc levels from baseline between groups and within groups $(\mathrm{p}=0.283)$. Median BMI and weight were significantly reduced in both groups, and those reductions were significantly higher in the Ma-Pi 2 group compared with the control group ( $<$ 0.001) (Table 4).

A non-parametric longitudinal data analysis of the daily FBG and PPBG evidenced a trend curve reduction in both groups over time $(\mathrm{p}<0.001)$, with a higher tendency in the macrobiotic Ma-Pi 2 diet group ( $<$ < 0.001). Furthermore, the duration and the type of diet positively influenced the reduction of both FBG and PPBG $(\mathrm{p}<0.001)$ (Figure 2).

The results of the multiple quantile regression analysis (adjusted for age, gender, BMI at baseline, and physical activity) are reported in Table 1. A significantly higher percentage reduction of $\mathrm{FBG}$, PPBG, and $\mathrm{HbA}_{1 \mathrm{c}}$ were associated with the Ma-Pi 2 diet, and a statistically significant higher effect on the percentage reductions in the same group was obtained for total cholesterol, LDLcholesterol and LDL/HDL ratio, BMI, weight, and waist and hip circumference compared with the control group. The Ma-Pi 2 diet group experienced a significantly greater reduction of HOMA-IR (adjusted for wrist circumference) compared with the control group. No statistically significant changes in HDL-cholesterol levels were noted in either group, whereas the control diet group showed a significantly higher effect in the reduction of triglyceride levels compared to the Ma-Pi 2 group even though a reduction in triglycerides levels was obtained in both groups, none of the study participants had triglyceride values in the higher range after intervention.

Table 2 shows the results obtained by comparing both groups in the achievement and maintenance of FBG and PPBG. The percentage of patients who achieved FBG and PPBG target levels was significantly higher in the MaPi 2 group compared with the control group. No significant difference was found in the percentage of patients that maintained the glycemic target level (both fasting and postprandial capillary glucose) between T0 and T21 (Figure 4). For some patients, OAD therapy had to be reduced to avoid hypoglycemia. A statistically significant reduction in OAD therapy occurred in the Ma-Pi 2 group compared with the control group ( $\mathrm{p}=0.018)$; from a total of 7 patients on sulfonylurea or glinide and/or DPP-4 inhibitor treatment at baseline, 5 suspended treatment (resulting in a total daily reduction of $8.5 \mathrm{mg}$ of glinide, $200 \mathrm{mg}$ glicazide, and $10 \mathrm{mg}$ glibencamide). There were no episodes of hypoglycaemia in both the intervention group and the control group even though in the Ma-Pi 2

Table 2 Number of patients who achieved target blood glucose levels after 21 days of dietary treatment

\begin{tabular}{|c|c|c|c|c|c|}
\hline \multirow[b]{2}{*}{ Fasting blood glucose (target value $\leq 110 \mathrm{mg} / \mathrm{dl}$ ) } & \multirow{2}{*}{$\begin{array}{c}\text { Ma-Pi } 2 \text { diet (n. 25) } \\
\text { n (\%) }\end{array}$} & \multirow{2}{*}{$\begin{array}{c}\text { Control diet (n. 26) } \\
\text { n (\%) }\end{array}$} & \multirow[b]{2}{*}{ Difference (\%) } & \multicolumn{2}{|c|}{$95 \% \mathrm{Cl}^{*}$} \\
\hline & & & & LL & UL \\
\hline Target achievement** & $19(100)$ & $9(45)$ & 55.00 & 33.20 & 76.80 \\
\hline Target maintenance** & $6(100)$ & $5(83.33)$ & 16.67 & -13.15 & 46.49 \\
\hline \multicolumn{6}{|l|}{ Post-prandial blood glucose (target value $\leq 140 \mathrm{mg} / \mathrm{dl}$ ) } \\
\hline Target achievement & $11(100)$ & $8(53.33)$ & 46.67 & 21.42 & 71.91 \\
\hline Target maintenance & $14(100)$ & $9(81.82)$ & 18.18 & -4.61 & 40.97 \\
\hline
\end{tabular}

*McNemar test. Coefficients are statistically significant when the $95 \% \mathrm{Cl}$ 's does not include zero.

**The percentage of patients that achieved the glycemic target level (both fasting and 2-h after lunch capillary glucose) between T0 and T21 and the percentage of patients that maintained the glycemic target level (both fasting and 2-h after lunch capillary glucose) between T0 and T21, in the Ma-Pi 2 group compared with the control group. 


\section{Fasting Blood Glucose}

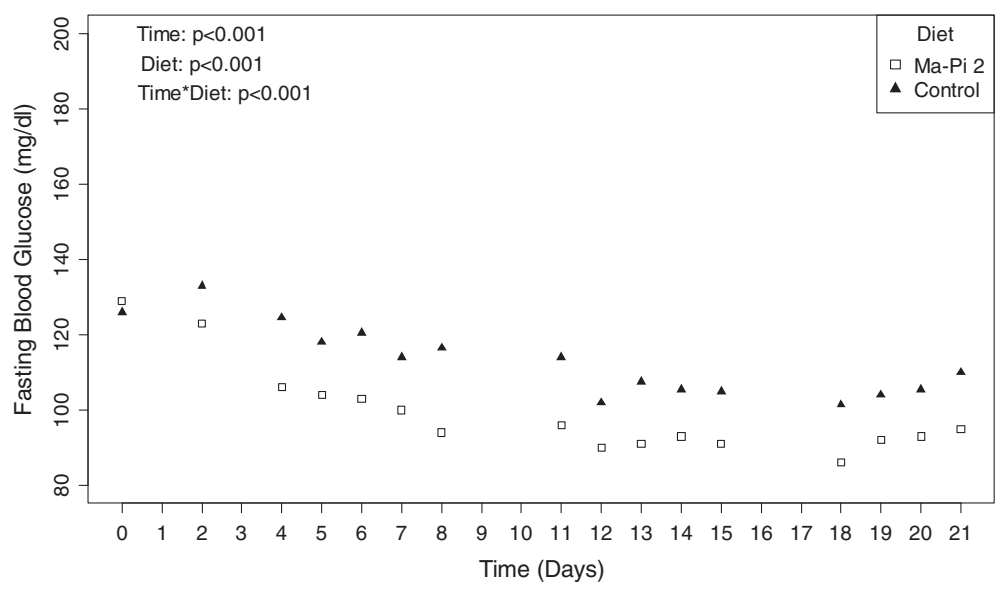

Post Prandial Capillary Glucose

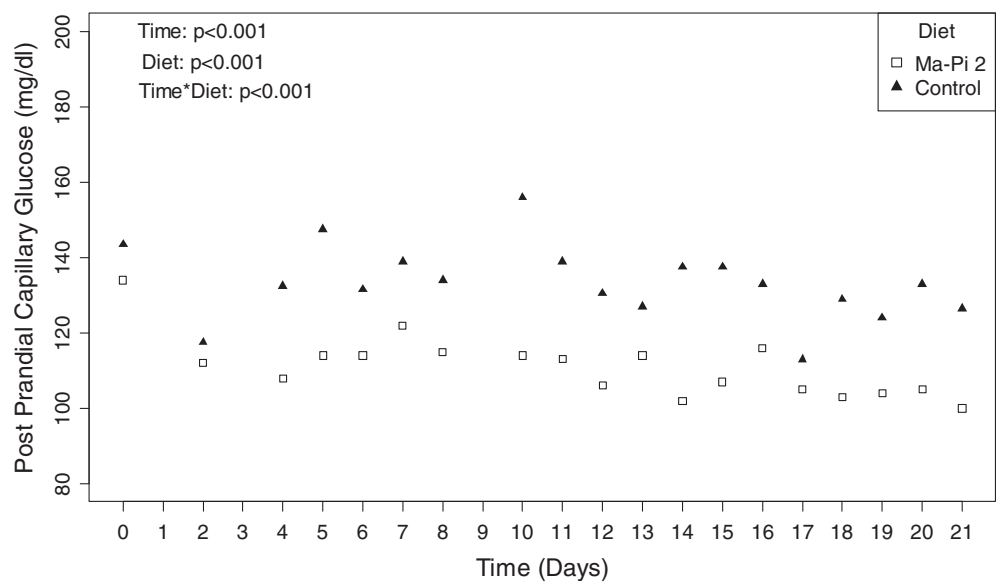

Figure $\mathbf{2}$ Linear distribution of the daily blood glucose values during the $\mathbf{2 1}$ days in and between groups. The figure represents the results of a non-parametric longitudinal analysis of all daily FBG and PPBG values between baseline and T21 in the Ma-Pi 2 group and the control group.

group there was a tendency for lower blood glucose levels. In the control group only 1 patient suspended OAD treatment (equating to a total reduction of $60 \mathrm{mg}$ glicazide). Compliance was good in all patients, with no meals missed by any patient in either group. There were no reported severe AEs. Pedometer readings revealed no significant difference in the intensity of physical activity or duration between the 2 groups.

\section{Discussion}

In overweight or obese patients with type 2 diabetes, a short-term (21 days) nutritional intervention trial using 2 different diets showed that both diets resulted in beneficial effects on metabolic parameters. The macrobiotic Ma-Pi 2 diet was associated with a greater reduction in fasting and post prandial plasma glucose, $\mathrm{HbA}_{1 \mathrm{c}}$, serum cholesterol, HOMA-IR, BMI, and waist and hip circumferences than the standard control diet.
Our study is the first randomized trial to assess and quantify the reported beneficial effects of the Ma-Pi 2 diet versus the standard nutritional recommendations for type 2 diabetes [25]. In this trial patients consuming the Ma-Pi 2 diet experienced a statistically significantly greater benefit in terms of reduced FBG, PPBG, $\mathrm{HbA}_{1 \mathrm{c}}$, and HOMA-IR, compared to patients receiving the control diet, suggesting that the Ma-Pi 2 macrobiotic diet is a more effective dietary intervention than the standard recommended diet for improving metabolic control in patients with type 2 diabetes. Also, significantly greater weight loss was obtained in the Ma-Pi 2 diet group compared with the control group, despite consumption of the same energy content in both diets. The Ma-Pi 2 diet was also higher in fiber content by up to $10 \mathrm{~g} / 1000 \mathrm{kcal}$ (50\%) than the control diet which may also have contributed to the greater weight loss in the Ma-Pi 2 diet group; Langlois et al. conducted a retrospective cohort study of 
Table 3 Baseline characteristics according to study group

\begin{tabular}{|c|c|c|c|}
\hline Median $[95 \% \mathrm{Cl}]$ & $\begin{array}{c}\text { Ma-Pi } 2 \text { diet } \\
\quad(n=25)\end{array}$ & $\begin{array}{l}\text { Control diet } \\
\quad(n=26)\end{array}$ & p value* \\
\hline Age (years) & $67[63.8 ; 70.2]$ & $65[62.2 ; 67.8]$ & 0.213 \\
\hline Male, n (\%) & $11(44)$ & $14(53,8)$ & $0.580^{\#}$ \\
\hline Duration of T2D (years) & $7[3.9 ; 10.01]$ & $4.5[1.1 ; 7.9]$ & 0.494 \\
\hline On Metformin, n (\%) & $13(61.9)$ & $20(90.9)$ & $0.034^{\#}$ \\
\hline On other OADs, n (\%) & $7(33.3)$ & $10(45.5)$ & $0.537^{\#}$ \\
\hline Fasting blood glucose (mg/dl) & $118[104.7 ; 131.3]$ & $127[115.2 ; 138.8]$ & 0.888 \\
\hline $\mathrm{HbA}_{1 \mathrm{c}}(\%)$ & $6.7[6.2 ; 7.2]$ & $6.8[6.6 ; 7.0]$ & 0.197 \\
\hline $\mathrm{HbA}_{1 \mathrm{c}}(\mathrm{mmol} / \mathrm{mol})$ & $50[44 ; 55]$ & $51[49 ; 53]$ & 0.228 \\
\hline HOMA-IR & $3.1[2.1 ; 4.0]$ & $3.3[2.1 ; 4.5]$ & 0.910 \\
\hline Total cholesterol (mg/dl) & $176[156.4 ; 195.6]$ & $180.5[160.7 ; 200.3]$ & 0.865 \\
\hline LDL cholesterol (mg/dl) & $102[86.5 ; 117.5]$ & $101.5[89.1 ; 113.9]$ & 0.749 \\
\hline HDL cholesterol (mg/dl) & $46[41.6 ; 50.4]$ & $48.5[44.5 ; 52.5]$ & 0.428 \\
\hline LDL/HDL ratio & $2.4[2.1 ; 2.7]$ & $2[1.7 ; 2.3]$ & 0.243 \\
\hline Triglycerides (mg/dl) & $114[83.7 ; 144.3]$ & $119[97.6 ; 140.4]$ & 0.644 \\
\hline $\mathrm{BMI}\left(\mathrm{kg} / \mathrm{m}^{2}\right)$ & $31.3[29.1 ; 33.5]$ & $32[29.5 ; 34.5]$ & 0.486 \\
\hline Weight (kg) & $81.1[73.7 ; 88.5]$ & $87[79.0 ; 94.9]$ & 0.713 \\
\hline Waist circumference (cm) & $107.6[102.3 ; 112.9]$ & $105.2[99.8 ; 110.6]$ & 0.963 \\
\hline Hip circumference $(\mathrm{cm})$ & $108.7[102 ; 115.4]$ & $109.7[104.7 ; 114.7]$ & 0.821 \\
\hline
\end{tabular}

*Wilcoxon rank sum test.

\#Fisher exact test.

Legend: All data showed are a median [95\% Confidence Interval $\mathrm{Cl}$ ] unless otherwise noted. Coefficients are statistically significant when the $95 \% \mathrm{Cl}$ 's does not include zero.

the Canadian population and found that dietary fiber intake was inversely related with incidence of obesity [32].

A reduction in total cholesterol, LDLc and LDL/HDL ratio was observed with both diets, but was significantly higher with the Ma-Pi 2 diet. This could be the result of a higher intake of wholegrain cereals; this is in line with a Cochrane review on the effect of wholegrain cereals on coronary heart disease that found that short-term dietary oatmeal intervention was associated with lower total cholesterol and LDLc [33].

The success of the control diet in improving metabolic control is supported by previous studies on Mediterranean

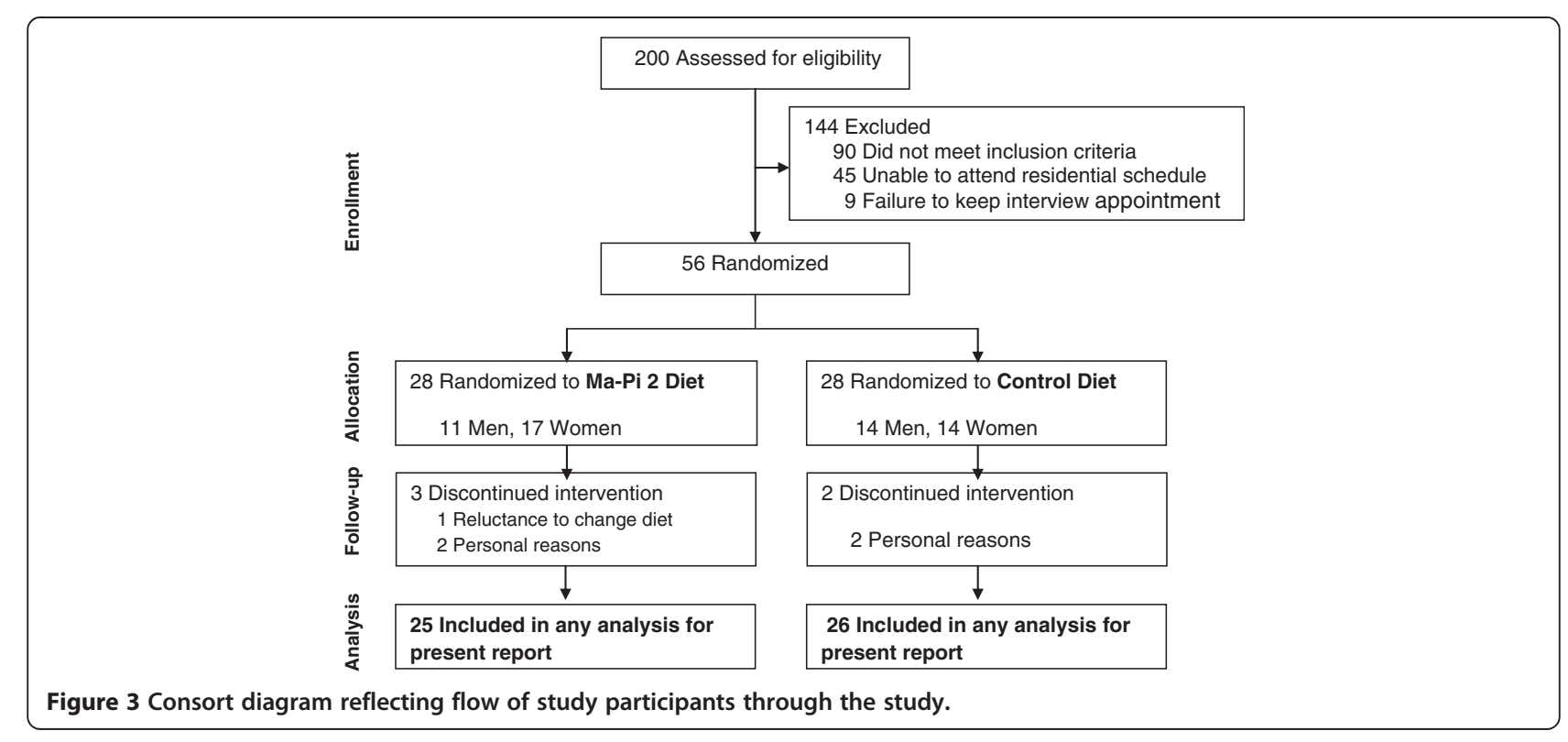


Table 4 Primary and secondary outcomes comparison between groups at baseline and after 21 days on the prescribed diets

\begin{tabular}{|c|c|c|c|c|c|c|c|c|c|}
\hline \multirow[t]{2}{*}{ Median $\left[1^{\text {st }}-3^{\text {rd }}\right.$ quartiles $]$} & \multicolumn{4}{|c|}{ Ma-Pi 2 diet $(n=25)$} & \multicolumn{5}{|c|}{ Control diet $(n=26)$} \\
\hline & Baseline & T21 & Absolute change & Percent change & Baseline & T21 & Absolute change & Percent change & $p$ value* \\
\hline $\begin{array}{l}\text { Fasting blood } \\
\text { glucose (mg/dl) }\end{array}$ & $129(111 ; 149)$ & $95(91 ; 100)$ & $34(21 ; 44)$ & $26.2(18.7 ; 34.1)$ & $126(112 ; 150)$ & $110(99 ; 115)$ & $22.8(8.1 ; 44.6)$ & $16.9(6.9 ; 30.1)$ & 0.073 \\
\hline $\begin{array}{l}\text { Post prandial blood } \\
\text { glucose }(\mathrm{mg} / \mathrm{dl})\end{array}$ & $134(112 ; 179)$ & $100(94 ; 106)$ & $34(18 ; 75.5)$ & $23.1(15.9 ; 42.9)$ & $144(128 ; 210)$ & $127(108 ; 151)$ & $15.3(-1.6 ; 58.6)$ & $8.7(-1.9 ; 50.3)$ & 0.035 \\
\hline $\mathrm{HbA}_{1 \mathrm{c}}(\%)$ & $6.7(6.2 ; 7.7)$ & $6.3(5.9 ; 7)$ & $0.4(0.2 ; 0.6)$ & $6.2(3.3 ; 8.3)$ & $6.8(6.4 ; 7.1)$ & $6.6(6.2 ; 7)$ & $0.2(0.1 ; 0.4)$ & $2.2(1.5 ; 5)$ & 0.002 \\
\hline HOMA-IR & $3.1(1.2 ; 4.1)$ & $0.98(0.61 ; 1.98)$ & $1.3(0.1 ; 2.9)$ & $51.4(11.7 ; 78.3)$ & $3.3(0.9 ; 4.6)$ & $1.6(1.2 ; 2.4)$ & $1.4(-0.2 ; 2.3)$ & $40.4(-21.9 ; 62)$ & 0.142 \\
\hline Total cholesterol (mg/dl) & $176(155 ; 217)$ & $120(102 ; 138)$ & $57(40 ; 65)$ & $32(23.8 ; 38.6)$ & $180.5(150.2 ; 210.8)$ & $154(133 ; 185)$ & $24(16 ; 43)$ & $12.3(9.9 ; 23)$ & $<0.001$ \\
\hline LDL cholesterol (mg/dl) & $102(84 ; 133)$ & $62(39 ; 69)$ & $45(33 ; 58)$ & $47.9(33.5 ; 53.6)$ & $101.5(84.8 ; 123.5)$ & $81(66 ; 105)$ & $20(12.3 ; 31.3)$ & $19.7(13.5 ; 27.8)$ & $<0.001$ \\
\hline HDL cholesterol (mg/dl) & $46(38 ; 52)$ & $42(36 ; 51)$ & $4(-1 ; 8)$ & $7.5(-2.2 ; 17.1)$ & $48.5(43 ; 55.8)$ & $47(40 ; 56)$ & $0.5(-2 ; 6.8)$ & $0.9(-4.4 ; 11.5)$ & 0.283 \\
\hline LDL/HDL ratio & $2.4(2 ; 3)$ & $1.3(0.9 ; 2.4)$ & $0.9(0.5 ; 1.3)$ & $38.5(29.3 ; 49.9)$ & $2(1.8 ; 2.6)$ & $1.8(1.3 ; 2.4)$ & $0.4(0.1 ; 0.7)$ & $17.2(5.9 ; 29.5)$ & $<0.001$ \\
\hline BMI $\left(\mathrm{kg} / \mathrm{m}^{2}\right)$ & $31.3(29.9 ; 36.8)$ & $29.5(28.2 ; 34.6)$ & $2(1.8 ; 2.4)$ & $5.9(5.4 ; 6.9)$ & $32(28.2 ; 35.9)$ & $30.8(27.3 ; 34.6)$ & $1(0.7 ; 1.3)$ & $2.9(2.4 ; 4.1)$ & $<0.001$ \\
\hline Weight (kg) & $81.1(75.6 ; 99.1)$ & $77(70 ; 94)$ & $5.5(4.4 ; 6)$ & $6.3(5.6 ; 7.2)$ & $87(79 ; 103.9)$ & $83(75 ; 100)$ & $2.8(2 ; 3.6)$ & $2.9(2.4 ; 4.2)$ & $<0.001$ \\
\hline Waist circumference (cm) & $107.6(97.9 ; 114.7)$ & $103(96 ; 112)$ & $4.2(1.4 ; 6.5)$ & $3.9(1.6 ; 5.3)$ & $105.2(101.6 ; 117.5)$ & $103(101 ; 113)$ & $2.3(0.9 ; 4)$ & $1.9(0.9 ; 2.9)$ & 0.046 \\
\hline Hip circumference $(\mathrm{cm})$ & $108.7(102.5 ; 23.8)$ & $105(99 ; 120)$ & $3.4(2 ; 5.2)$ & $3.1(1.8 ; 4)$ & $109.7(102.6 ; 118.4)$ & $108(101 ; 118.4)$ & $1.8(1 ; 2.5)$ & $1.6(0.8 ; 2.4)$ & 0.006 \\
\hline
\end{tabular}

Legend: *P-value by Wilcoxon rank-sum test are referred to percent changes between the two treatment groups. 


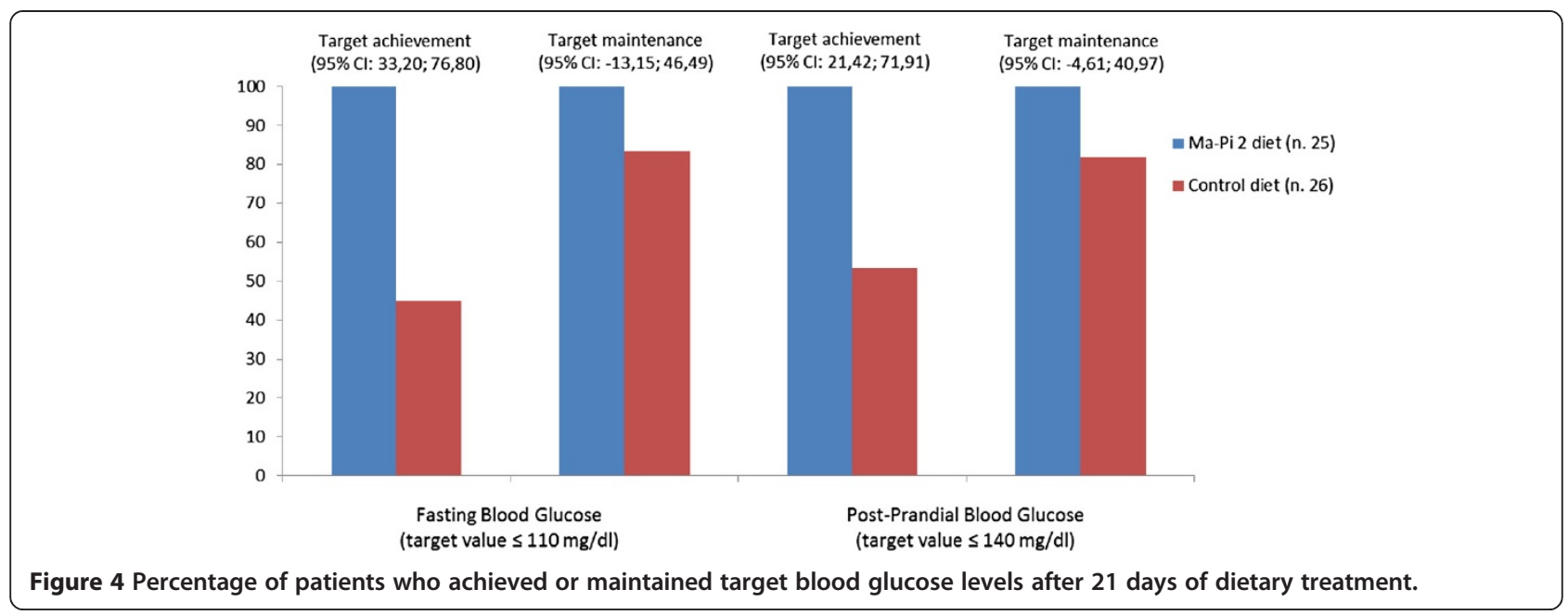

diets. A systematic review and meta-analysis found significant improvement in glycemic control in low-carbohydrate, Mediterranean, and high-protein diets and a greater weight loss in low-carbohydrate and Mediterranean diets compared with their respective control diets [34]; A short trial on the effect of a high-protein/low-carbohydrate diet on glucose control showed a reduction in circulating glucose concentration in patients with untreated type 2 diabetes [35]; A Mediterranean diet, rich in monounsaturated fatty acids and in complex carbohydrate but not high in protein was associated with lower $\mathrm{HbA}_{1 \mathrm{c}}$ levels and 2 hour postmeal glucose levels independently of variations in age, adiposity, energy intake, and physical activity in 901 patients with type 2 diabetes [36].

Overall the positive results obtained with the two diets in our short-term study may be explained in part by the wellbeing (emotional and physical) state of our patients since they were located close to the sea, had a strict control on the caloric intake, perform regular (monitored) physical activity improving their overall quality of life. The greater effect of the Ma-Pi 2 diet compared to the control diet on a number of metabolic parameters may be due to several factors, from changes in inflammation and/or oxidative stress [37] to the composition of microbiota [22]. Ongoing studies should elucidate all these issues, hence a long-term sustainability of the Ma-Pi 2 diet, in particular the acceptance and adherence of the patient to the diet, the implying costs in the patient management remain to be proven.

Patient compliance and adherence to recommended therapeutic diets for diabetes are essential for the diets to be able to produce clinically-significant improvements in patient outcomes, and positive results achieved with diets in clinical trials are often difficult to replicate in real-life practice [38]. In the study presented here, participants attended 2-hour meetings daily for nutritional education and cooking instructions in their respective hotels conducted by a physician and a registered dietitian and/or a cooking instructor. This was done to encourage continuation of the respective diets once the trial was completed.

Our study had a number of limitations including short duration, lack of blinding, and relatively small sample size. The short duration was due to the difficulty in accommodating participants for 24 hours per day and requiring them not to leave their respective hotels for the duration of the trial. A longer-term trial of this type is unlikely to be successful due to the lower number of volunteers and higher number of dropouts that would be likely with increased duration. Participant blinding was impossible due to the distinct differences in the ingredients and therefore taste and appearance of the 2 diets used. Similarly, it was also not possible to blind the medical staff present at the hotels. However, the investigators involved in follow-up and blood testing were blinded to the treatment groups.

\section{Conclusions}

All patients in the Ma-Pi 2 diet group had their glucose levels reduced to the point of being comparable to subjects without type 2 diabetes (target values), following 21-day intervention in a supervised environment. Further long-term follow-up studies are needed to confirm these results and the use of this diet in real-life practice must also be investigated to demonstrate patient acceptance and compliance.

\section{Availability of supporting data}

The data sets supporting the results of this article are included within the article and its additional files.

\section{Consent}

Written informed consent was obtained from the patient for the publication of this report and any accompanying images. 


\section{Additional file}

\section{Additional file 1: MA-PI 2 Macrobiotic Diet Daily Meal Plans and} Recipes.

\section{Abbreviations}

(FBG): Fasting blood glucose; (PPBG): Post-prandial blood glucose; (HbA1c): Glycated hemoglobin; (IR): Insulin resistance; (BMI): Body mass index; (95\% Cl): 95\% confidence intervals; (LDLC): Low-density lipoprotein cholesterol; (HDLc): High-density lipoprotein cholesterol; (LDL/HDL ratio): Low-density lipoprotein cholesterol/ High-density lipoprotein cholesterol ratio; (IDF): International Diabetes Federation; (ADA): American Diabetes Association; (OADs): Oral hypoglycemic drugs; (INRAN): National Institute for Food and Nutrition Research; (T0): Baseline; (T21): The $21^{\text {st }}$ day of treatment; (HOMA-IR): Homeostatic model assessment; (AEs): Reported adverse events; (SD): Standard deviation; (ITT) analysis: An intention-to-treat; (DPP-4): Dipeptidyl peptidase-4 inhibitor.

\section{Competing interests}

The authors declare that they have no competing interests.

\section{Authors' contributions}

AS conducted the study; recruited subjects; collected data; and wrote the manuscript. RDT recruited subjects, conducted the study, and collected data. YMK contributed to study design and to the writing of the manuscript. ER contributed to patients follow-up and reviewed the manuscript. LF recruited subjects, contributed to patients follow-up and reviewed the manuscript. SF analyzed data and contributed to the writing of the manuscript. SA analyzed blood samples and reviewed the manuscript. VF: collected data, and contributed to the writing of the manuscript. FC collected data, and contributed to the writing of the manuscript. VR collected data and contributed to the writing of the manuscript. CP conducted the study, collected data and reviewed the manuscript. ES and RG analyzed data and contributed to the writing and reviewed the manuscript. SM and FF contributed to the study design, to the discussion and reviewed the manuscript. MP conceived and contributed to the study design, and reviewed the manuscript. PP conceived and designed the study, contributed to the discussion and reviewed and edited the manuscript. PP is the guarantor of this work and, as such, had full access to all the data in the study and takes responsibility for the integrity of the data and the accuracy of the data analysis. All authors read and approved the final manuscript.

\section{Funding/Support}

This study was supported by "Un Punto Macrobiotico Association", a charity/ not-for-profit organization that provided the food required for the trial and supported the cost of blood analyses. Un Punto Macrobiotico Association.

\section{Role of the sponsors}

The research sponsors played no role in the design or conduct of the study, collection, management, analysis or interpretation of the data.

Parts of this study were presented in abstract form at the World Diabetes Congress of the International Diabetes Federation, Melbourne, Australia, 2-6 December 2013.

The authors would like to acknowledge Duncan Marriott and Clare Gurton (Rx Communications, Mold, UK) for medical writing assistance with the preparation of this article. Un Punto Macrobiotico Association has contributed to the costs of writing assistance.

\section{Author details}

'Department of Endocrinology and Diabetes, University Campus Bio-Medico, Via Alvaro del Portillo 21, 00128 Rome, Italy. ${ }^{2}$ Unit of Dietology and Diabetology, Sandro Pertini Hospital, Via dei Monti Tiburtini 385, 00157 Rome, Italy. ${ }^{3}$ Department of Laboratory Medicine, University Campus Bio-Medico, Rome, Italy. ${ }^{4}$ Department of Biochemistry and Physiology, Institute of Nutrition and Food Hygiene, Infanta 1158, 10300 Havana, Cuba. ${ }^{5}$ Clinical Assay Direction, Finlay Institute, Avenue 27, No. 19805, La Coronela, La Lisa 11600, Havana, Cuba. ${ }^{6}$ Center of Epidemiology, Biostatistics and Medical Information Technology, Polytechnic Marche University, Via Tronto 10A, 60020 Ancona, Italy. ${ }^{7}$ Department of Clinical Sciences, La Sapienza University II Faculty, Via di Grottarossa 1035/1039, 00189 Rome, Italy.
${ }^{8}$ International Study Center for Environment, Agriculture, Food, Health and Economics, Via San Nicola, 62029 Rome, Italy.

Received: 19 April 2014 Accepted: 17 August 2014 Published: 25 August 2014

\section{References}

1. Zhang P, Zhang X, Brown J, Vistisen D, Sicree R, Shaw J, Nichols G: Global healthcare expenditure on diabetes for 2010 and 2030. Diabetes Res Clin Pract 2010, 87:93-301.

2. Diabetes Prevention Program Research Group, Knowler WC, Fowler SE, Hamman R, Christophi CA, Hoffman HJ, Brenneman AT, Brown-Friday JO, Goldberg R, Venditti E, Nathan DM: 10-year follow-up of diabetes incidence and weight loss in the Diabetes Prevention Program Outcomes Study. Lancet 2009, 374:1677-1686.

3. Orzech KM, Vivian J, Huebner Torres C, Armin J, Shaw SJ: Diet and exercise adherence and practices among medically underserved patients with chronic disease: variation across four ethnic groups. Health Educ Behav 2013, 40:56-66.

4. Trapp C, Barnard N, Katcher H: A plant-based diet for type 2 diabetes: scientific support and practical strategies. Diabetes Educ 2010, 36:33-48.

5. Jenkins DJ, Kendall CW, Marchie A, Jenkins AL, Augustin LS, Ludwig DS, Barnard ND, Anderson JW: Type 2 diabetes and the vegetarian diet. Am J Clin Nutr 2003, 78:610-616.

6. Farmer B, Jonson BT, Fulgoni V, Rainulile AJ, Leipa GU: A vegetarian dietary pattern as a nutrient-dense approach to weight management: an analysis of the National Health and Nutrition Examination Survey 1999-2004. J Am Diet Assoc 2011, 111:819-827.

7. Barnard ND, Cohen J, Jenkins DJ, Turner-McGrievy G, Glode L, Jaster B, Seidl K, Green AA, Talpers S: A low-fat vegan diet improves glycemic control and cardiovascular risk factors in a randomized clinical trial in individuals with type 2 diabetes. Diabetes Care 2006, 29:1777-1783.

8. Shyam S, Arshad F, Abdul Ghani R, Wahab NA, Safii NS, Nisak MY, Chinna K, Kamaruddin NA: Low glycaemic index diets improve glucose tolerance and body weight in women with previous history of gestational diabetes: a six months randomized trial. Nutr J 2013, 24(12):68

9. American Diabetes Association: Standards of medical care in diabetes2013 (position statement). Diabetes Care 2013, 36:11-66.

10. Evert AB, Boucher JL, Cypress M, Dunbar SA, Franz MJ, Mayer-Davis EJ, Neumiller JJ, Nwankwo R, Verdi CL, Urbanski P, Yancy WS Jr, American Diabetes Association: Nutrition therapy recommendations for the management of adults with diabetes. Diabetes Care 2013, 36:3821-3842

11. Muñoz-Pareja M, León-Muñoz LM, Guallar-Castillón P, Graciani A, LópezGarcía E, Banegas JR, Rodríguez-Artalejo F: The diet of diabetic patients in Spain in 2008-2010: Accordance with the main dietary recommendationsa cross-sectional study. PLoS One 2012, 7:e39454.

12. Ohsawa G: Le zen macrobiotique ou l'art du rajeunissement et de la longévité Paris: Librairie Philosophique J Vrin; 2004.

13. Craig WJ, Mangels AR, American Dietetic Association: Position of the American dietetic association: vegetarian diets. J Am Diet Assoc 2009, 109:1266-1282.

14. Slavin J: Fiber and prebiotics: Mechanisms and health benefits. Nutrients 2013, 5:1417-1435.

15. Porrata C, Sánchez J, Correa V, Abuín A, Hernández-Triana M, DacostaCalheiros RV, Díaz ME, Mirabal M, Cabrera E, Campa C, Pianesi M: Ma-pi 2 macrobiotic diet intervention in adults with type 2 diabetes mellitus. MEDICC Rev 2009, 11:29-34.

16. Connor H, Annan F, Bunn E, Frost G, McGough N, Sarwar T, Thomas B, Nutrition Subcommittee of the Diabetes Care Advisory Committee of Diabetes UK: The implementation of nutritional advice for people with diabetes. Diabetes Med 2003, 20:786-807.

17. Delzenne NM, Cani PD: Gut microbiota and the pathogenesis of insulin resistance. Curr Diab Rep 2011, 11:154-159.

18. Slavin JL: Plausible mechanism for the protectiveness of whole grains. Am J Clin Nutr 1999, 70:459-463.

19. Turner-McGrievy GM, Bernard ND, Cohen J, Jenkins DJ, Gloede L, Green AA Changes in nutrient intake and dietary quality among participants with type 2 diabetes following a low-fat vegan diet for 22 weeks. J Am Diet Assoc 2008, 108:1636-1645. 
20. Diamant $M$, Blaak EE, de Vos WM: Do nutrient-gut-microbiota interactions play a role in human obesity, insulin resistance and type 2 diabetes? Obes Rev 2011, 12:272-281.

21. Kootte RS, Vrieze A, Holleman F, Dallinga-Thie GM, Zoetendal EG, de Vos WM, Groen AK, Hoekstra JB, Stroes ES, Nieuwdorp M: The therapeutic potential of manipulating gut microbiota in obesity and type 2 diabetes mellitus. Diabetes Obes Metab 2012, 14:112-120.

22. Zhang $X$, Shen D, Fang Z, Jie Z, Qiu X, Zhang C, Chen Y, Ji L: Human gut microbiota changes reveal the progression of glucose intolerance. PLoS One 2013, 8:e71108.

23. Porrata-Maury C, Hernández-Triana M, Ruiz-Alvarez V, Díaz-Sánchez ME, Fallucca F, Bin W, Baba-Abubakari B, Pianesi M: Ma-Pi 2 macrobiotic diet and type 2 diabetes mellitus: pooled analysis of short-term intervention studies. Diabetes Metab Res Rev 2014, 30:55-66.

24. Fallucca F, Porrata C, Fallucca S, Pianesi M: Influence of diet on gut microbiota, inflammation and type 2 diabetes mellitus. First experience with macrobiotic Ma-Pi 2 diet. Diabetes Metab Res Rev 2014, 30:48-54.

25. Associazione Medici Diabetologici, Società Italiana di Diabetologia (Ed): Standard italiani per la cura del diabete mellito. Torino: Edizione per la Medicina Generale Infomedica; 2011.

26. National Cholesterol Education Program (NCEP) Expert Panel on Detection, Evaluation, and Treatment of High Blood Cholesterol in Adults (Adult Treatment Panel III): Third Report of the National Cholesterol Education Program (NCEP) Expert Panel on Detection, Evaluation, and Treatment of High Blood Cholesterol in Adults (Adult Treatment Panel III) final report. Circulation 2002, 106:3143-3421.

27. Gnagnarella P, Parpinel M, Salvini S, Franceschi S, Palli D, Boyle P: The update of the Italian food composition database. J Food Composition Anal 2004, 17:509-522.

28. Haffner SM, Miettinen H, Stern MP: The homeostasis model in the San Antonio Heart Study. Diabetes Care 1997, 20:1087-1092.

29. Koenker R: Quantile Regression. New York: Cambridge University Press; 2005.

30. Capizzi M, Leto G, Petrone A, Zampetti S, Papa RE, Osimani M, Spoletini M, Lenzi A, Osborn J, Mastantuono M, Vania A, Buzzetti R: Wrist circumference is a clinical marker of insulin resistance in overweight and obese children and adolescents. Circulation 2011, 123:1757-1762.

31. Jahangiri Noudeh Y, Hadaegh F, Vatankhah N, Momenan AA, Saadat N, Khalili D, Azizi F: Wrist circumference as a novel predictor of diabetes and prediabetes: results of cross-sectional and 8.8-year follow-up studies. J Clin Endocrin Metab 2013, 98:777-784.

32. Langlois K, Garriguet D, Findlay L: Diet composition and obesity among Canadian adults. Health Rep 2009, 20:11-20.

33. Kelly SAM, Summerbell CD, Brynes A, Whittaker V, Frost G: Wholegrain cereals for coronary heart disease. Cochrane Database Syst Rev 2007, 2:CD005051.

34. Ajala O, English P, Pinkney J: Systematic review and meta-analysis of different dietary approaches to the management of type 2 diabetes. Am J Clin Nutr 2013, 97:505-516.

35. Gannon MC, Nuttall FQ: Effects on a high protein, low carbohydrate diet on blood glucose control in people with type 2 diabetes. Diabetes 2004, 53:2375-2382

36. Esposito K, Maiorino MI, Di Palo C, Giugliano D, for the Campanian Post-Prandial Hyperglycemia Study Group: Adherence to a Mediterranean diet and glycaemic control in type 2 diabetes mellitus. Diabetic Med 2009, 26:900-907.

37. Vlassara H, Cai W, Serrano EJ, Shobha MS, Uribarri J, Woodward M, Striker GE: Managing chronic inflammation in the aging diabetic patient with CKD by diet or sevelamer carbonate: a modern paradigm shift. J Gerontol A Biol Sci Med Sci 2012, 67:1410-1416.

38. Lakerveld J, Bot SD, Chinapaw SD, van Tulder MW, Kostense PJ, Dekker JM, Nijpels G: Motivational interviewing and problem solving treatment to reduce type 2 diabetes and cardiovascular disease risk in real life: a randomized controlled trial. Int J Behav Nutr Phys Act 2013, 10:47.

\section{doi:10.1186/1743-7075-11-39}

Cite this article as: Soare et al:: The effect of the macrobiotic Ma-Pi 2 diet vs. the recommended diet in the management of type 2 diabetes: the randomized controlled MADIAB trial. Nutrition \& Metabolism 2014 11:39.

\section{Submit your next manuscript to BioMed Central and take full advantage of:}

- Convenient online submission

- Thorough peer review

- No space constraints or color figure charges

- Immediate publication on acceptance

- Inclusion in PubMed, CAS, Scopus and Google Scholar

- Research which is freely available for redistribution 